\section{Category}

Metals in Synthesis

\section{Key words}

deoxygenation

secondary alcohols

stannanes

D. H.R. BARTON*, S. W. MCCOMBIE* (IMPERIAL COLLEGE LONDON, UK)

A New Method for the Deoxygenation of Secondary Alcohols

J. Chem. Soc., Perkin Trans. 1 1975, 16, 1574-1585.

\title{
Radical-Driven Deoxygenation of Secondary Alcohols: The Barton-McCombie Reaction
}

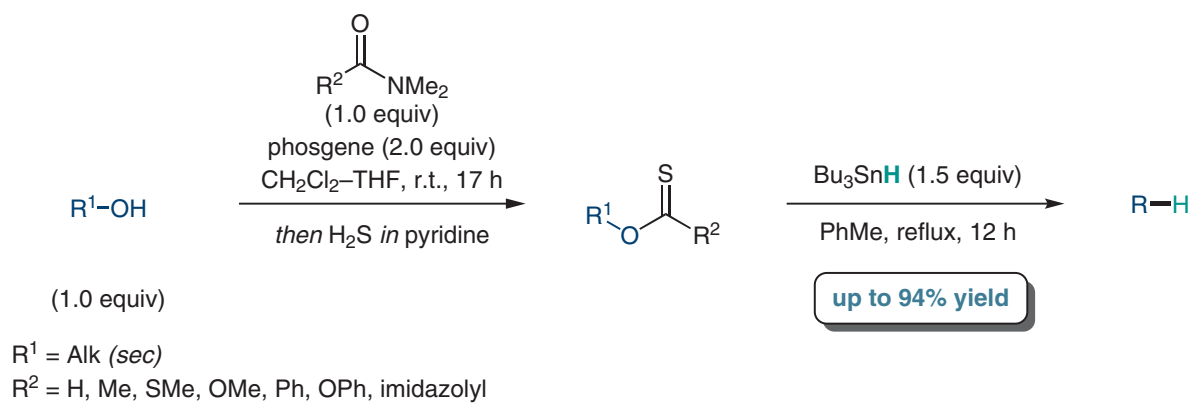

Proposed mechanism:
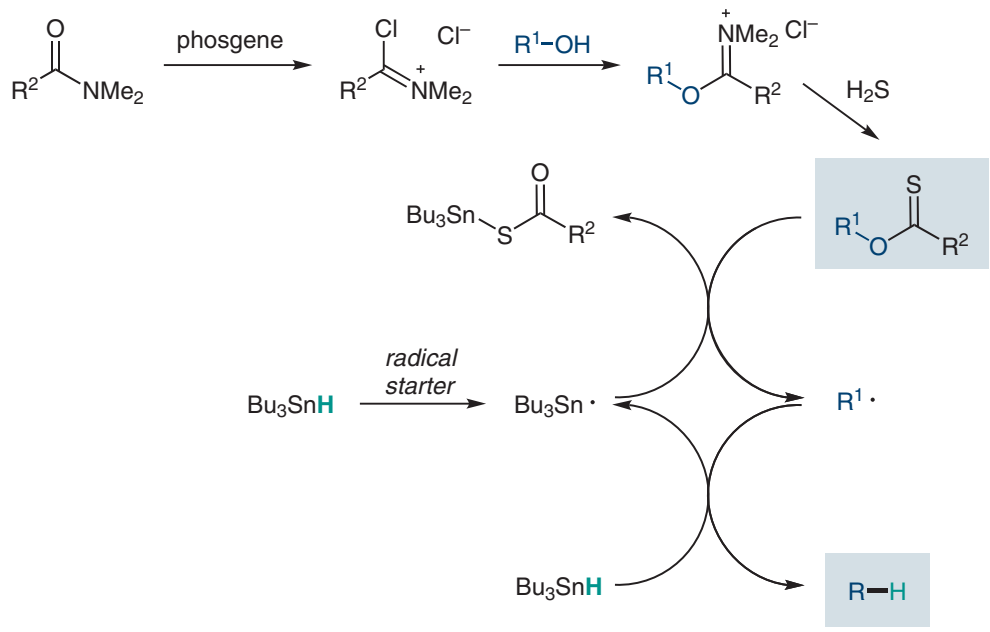

Selected examples:

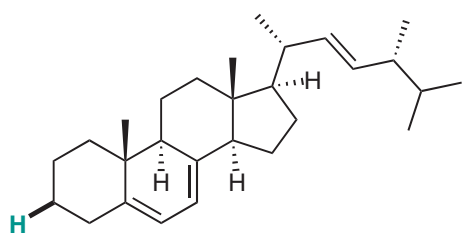

$67 \%$ yield from ergosterol

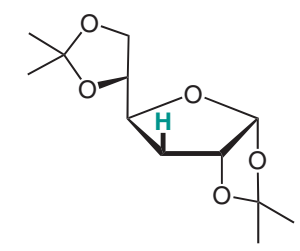

$85 \%$ yield from $\alpha$-D-glucofuranose

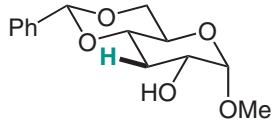

$70 \%$ yield

from $\alpha$-D-glucopyranoside
Significance: The authors reported a very broadly applicable method for the deoxygenation of secondary alcohols, providing complex hydrocarbons in high yields. The alcohol thereby has to be activated by transforming it into its corresponding thioester.
Comment: By using a radical mechanism and the favorable formation of an S-Sn bond, these thioesters can be deoxygenated. This concept has been revived in the Barton-McCombie decarboxylation (J. Chem. Soc., Chem. Commun.1980, 15, 732). 